\title{
Prerequisites for Community-based Disaster Risk Management in Iran
}

\author{
Ebrahim Babaei Rayeni ${ }^{1} \oplus$, Mohammad Mehdi Pour Saeed ${ }^{2} \oplus$ Mehdi Kazemi $^{3} \oplus$, \\ Mehdi Ebrahimi Nejad Rafsanjani ${ }^{3} \mathbb{C}$
}

Date of submission: 29 May, $2021 \quad$ Date of acceptance: 21 Jun, 2021

\begin{abstract}
INTRODUCTION: Natural disasters disrupt people's lives, bringing about serious economic and social losses. Disaster risk management is a set of measures, including planning, decisionmaking, accountability, and operational activities at all levels. Moreover, it is of considerable significance to take advantage of social capacities and community participation before, during, and after disasters. The present study aimed to explain the prerequisites of community-based disaster risk management in Iran in 2020.

METHODS: This data-driven qualitative study was conducted using Strauss and Corbin's systematic approach. The statistical population included all disaster management experts and non-governmental organizations in universities, the National Disaster Management Organization, the provincial disaster management departments, and senior managers of the Red Crescent Society. Out of this population, 22 subjects were purposefully selected via snowball sampling taking into account the geographical, climatic, cultural, social, and religious diversity of different regions of the country. The data were collected via semi-structured interviews and analysed using open coding, axial coding, and selective coding.

FINDINGS: Based on the obtained results, the prerequisites of community-based disaster risk management include: "legal obligation", "public sensitization", "strategic planning", "public participation", "social capacity building", " building cohesion and empathy ", "action (prevention, preparedness, needs assessment, planning, and response", "formation and development of expert teams", "logistics forecasting and equipment", "preparation", and attention to geographical conditions"."
\end{abstract}

Original Article

CONCLUSION: As evidenced by the obtained results, the required measures for the successful implementation of community-based disaster risk management can be assigned to two categories: The first one encompasses the measures that require structural changes and law reform and are taken at the national level and National Disaster Management Organization of the country. The second type of measure must be implemented at the local and operational management levels.

Keywords: Community-based; Disaster Management; Iran; Prerequisite.

How to cite this article: Babaei Rayeni E, Pour Saeed MM, Kazemi M, Ebrahimi Nejad Rafsanjani M. Prerequisites for Community-based Disaster Risk Management in Iran. Sci J Rescue Relief 2021; 13(3): 187-92.

\section{Introduction}

ran is one of the 10 most disaster-prone

I countries in the world (1); therefore, it is of utmost importance to draw on unsuccessful experiences and take advantage of effective measures implemented at home and abroad (2). There are two schools of thought about disaster risk management. One of them believes in the necessity of a top-down system with a precise and defined hierarchy in the government body (3). Based on this notion, contingency planning is a top-down process from the national level to the regional and then local levels (4).

The other school is based on the premise that disaster risk management will not be of acceptable

\footnotetext{
- PhD Student of Disaster Management, Shahid Bahonar University of Kerman, Kerman, Iran

2- Assistant Professor, Shahid Bahonar University of Kerman, Kerman, Iran

- Associate Professor, Shahid Bahonar University of Kerman, Kerman, Iran

Correspondence to: Mohammad Mehdi Pour Saeed, Email: poursaeed@uk.ac.ir
} 
quality without the cooperation of people and citizens. Therefore, disaster risk management should be institutionalized in the society, in which case there is a limited coordination center at the top and other affairs are performed by the citizens (5). A region is valued only by its inhabitants who can guarantee the preservation of these values. In fact, community-based disaster management reflects the participation of communities to manage disasters, creating a safe and resilient society with a strong economy and high quality of life (6).

In this management system, local people are regarded as a potential capacity whose participation and cooperation guarantee sustainability. Moreover, development and scientific implementation based on mutual respect and trust will ensure the reduction of damages and losses caused by disasters (7). Community-based disaster management is often recognized as the most powerful and highly adaptable approach at the local level which is initially affected by environmental hazards. The identification of shared strengths and weaknesses can play a critical role in the successful implementation of this approach in target communities (8). The hazards which threaten at-risk communities can be mitigated drawing on the capacity of people and vulnerable groups, as well as involving stakeholders by bringing about considerable changes in social relations and structures (9).

The prerequisites for community-based disasters management in the country have not been coherently explained yet. Therefore, emergency management decision-makers have remained unaware of the crucial role of public participation and harnessing the enormous capacity of local groups in different stages of disaster management (before, during, and after disasters). In light of the aforementioned issues, to fill this research gap, the present study aimed to explain the prerequisites for community-based disaster management in Iran in 2020.

\section{Methods}

This data-driven qualitative study was conducted using Strauss and Corbin's systematic approach. The statistical population included all disaster management experts and nongovernmental organizations in universities, the National Disaster Management Organization, the provincial disaster management departments, and senior managers of the Red Crescent Society. Out of this population, 22 subjects were purposefully selected via snowball sampling taking into account the geographical, climatic, cultural, social, and religious diversity of different regions of the country. Since the target group was merely restricted to experts, only those who met the inclusion criteria were selected for the interview.

The inclusion criteria were as follows: a $\mathrm{PhD}$ or a master's degree in related fields, at least 10 years of experience in relevant departments or participation in national or international disasters and teaching disaster management topics, as well as familiarity with the culture and social customs of the target community. Therefore, the research sample was selected via purposive sampling from all over the country. Subsequently, the final participants were determined using the theoretical sampling method. The logic and purpose of theoretical sampling are determined by the type of coding. In open coding, no concept is theoretically recorded. Considering that the researcher initially aimed to achieve open codes, sampling continued without restriction until the formation of initial categories and their accurate description. In other words, the logic of sampling in the final stages was the completion of categories. In theoretical sampling, data collection should cease with the saturation of categories.

The data were collected via semi-structured interviews and to analyze the qualitative data, the recorded interviews were transcribed in detail, followed by open coding. Line-by-line data analysis, which was described by Strauss and Carbin (1998) as the most accurate type of coding, was used to analyze the interviews and assign open codes. After 20 interviews, the researcher found that no new interview code could be obtained; nonetheless, two additional interviews were conducted to ensure data saturation. Therefore, the sample size of this study included 22 cases. The analysis steps were as follows: the open codes were initially textracted; thereafter, the subcategories were obtained by performing analysis and conceptualization, and finally, they were presented as general categories.

\section{Findings}

The frequency distribution of the interviewees based on their degree and years of activity in emergency management is presented in Table 1 . The interviewees comprised 22 people with a mean age of 54 years, bachelor's degrees and above in 
Table 1. Frequency distribution of interviewees by degree and years of activity related to emergency management

\begin{tabular}{ccccccc} 
Education & \multicolumn{5}{c}{ History of activities related to disaster risk management } \\
& $\mathbf{1 0 - 1 4}$ years & $\mathbf{1 5 - 2 4}$ years & $\mathbf{2 5 - 3 4}$ years & $\mathbf{3 5 - 4 0}$ years & Total \\
\hline Bachelor's degree & - & - & - & 2 & 2 \\
Master's degree & 1 & 4 & 1 & - & 6 \\
PhD in Medicine & & 1 & 3 & - & 2 \\
PhD & 2 & 5 & 3 & 12 \\
\hline
\end{tabular}

Table 2. Prerequisites for community-based crisis management from the perspective of experts \begin{tabular}{l|ll} 
Main categories & Sub-categories
\end{tabular} Legal obligation interaction, the delegation of authority to local teams, supervision and support of responsible agencies

Public sensitization

Explaining high disaster risk of the country, recalling past disasters, traumatic loss caused by disasters, the extent of damage by disasters in the past, raising public awareness on various disasters

Modeling, social participation, policy-making, financing, development and implementation of community-based activities and programs, Selection and training

Strategic planning of local disaster managers, using local human resources, receiving feedback and performance assessment, setting priorities, division of labor and unity of management

Attracting public participation

Social capacity building

Creating cohesion and empathy

Action (prevention, preparedness, needs assessment, planning, response)

Formation and development of specialized teams

Logistics forecasting and equipment

Preparation

Considering geographical conditions
Public call, facilitating teamwork, maximum participation (social systems, people assemblies, local associations, trust-building, raising motivation

Development of community service activities, social accountability

Strengthening altruistic behaviors, attention to common values, religious, social, and cultural adaptation and interaction, coordination and cohesion among people's assemblies, Synergy between government agencies and public institutions

Effective actions for the National disaster Risk Reduction Program, practical action in line with the Emergency Preparedness and Response Program

Emergency Response Plan (ERP), Developing Emergency Operations Plan (EOP), Implementation of National Reconstruction and Rehabilitation Plan

Formation of an emergency response team, the establishment of a local emergency operations center (EOC), Training local disaster managers and allocating responsibilities, forming specialized rescue teams in accordance with the needs of the region, building relief teams

Preparing rescue operation equipment, Providing relief supplies, personal protective equipment, the storage place of relief equipment and supplies, communication equipment, logistic support and supply

Operational exercises and dynamism, Improvement of the mental and psychological readiness of the members, increasing motivation

Paying attention to the geographical and climatic diversity of the country, investigating the special conditions of the region, assessing the regional risks various fields of disaster management. The subjects had 10-40 years (average 23.86 years) of work experience in disaster management activities at various national and international levels.

Table 2 displays the final categories extracted from interviews with experts to explain the prerequisites for community-based disaster management. The line-by-line analysis of the interviews yielded 630 open codes, and after the final analysis, 11 main categories and 54 subcategories were obtained.

\section{Discussion and Conclusion}

The current study aimed to explain the 
prerequisites for community-based disaster management in Iran. The necessity of this issue has led to the formation and strengthening of community-based approaches to disaster management. Therefore, community-based activities (bottom-top) should be seriously on the agenda of governments (11). In the communitybased approach, apart from risk identification by local residents, efforts are made to engage influential individuals and groups in all stages of disaster management (12).

In fact, the main purpose of this approach was to involve local people in planning, policymaking, coordination, control, and organization of disaster management under the guidance of the government (13). So far, some studies have been conducted on the importance and necessity of community-based measures in disaster management. Nevertheless, the majority of them have focused on the benefits and positive effects of these measures. However, the present study has explained the prerequisites for communitybased disaster management in a coherent manner.

As illustrated in Table 2, prerequisites for community-based disaster management are as follows: "legal obligation" through legislation, announcing bylaws to responsible organizations, coordination and interaction, delegation of authority to local teams, supervision and support of responsible bodies; "public sensitization" through such measures as explaining high disaster risk of the country, recalling past disasters, traumatic loss caused by disasters, the extent of damage by disasters in the past, raise public awareness on various disasters; "Strategic planning" through modeling, social participation, policy-making, financing, development and implementation of community-based activities and programs, selection and training of local disaster managers, using local human resources, receiving feedback and performance assessment, setting priorities, division of labor and unity of management; "attracting citizen participation" by public call, facilitating team work, maximum participation (social systems, people assemblies, local associations, Trust building, raising motivation; "social capacity building" by the development of community service activities, social accountability; "creating cohesion and empathy" by strengthening altruistic behaviors, attention to the shared values, religious, social, and culture adaptation and interaction, coordination and cohesion among people's assemblies, synergy between government agencies and public institutions; "action (prevention, preparedness, needs assessment, planning, response)" by effective actions for National disaster Risk Reduction Program, practical action in line with the Emergency Preparedness and Response Program, Emergency Response Plan (ERP), developing Emergency Operations Plan (EOP), implementation of National Reconstruction and Rehabilitation Plan; " development of specialized teams" with the formation of an emergency response team, the establishment of a local emergency operations center (EOC), training local disaster managers and allocating responsibilities, forming specialized rescue teams in accordance with the needs of the region, building relief teams; "logistic forecasting and equipment " by preparing rescue operation equipment, providing relief supplies, personal protective equipment, storage place of relief equipment and supplies, communication equipment, logistic support and supply; "preparation" through operational exercises and dynamism, improvement of members' mental readiness, and "paying attention to the geographical conditions" taking into account the geographical and climatic diversity of the country, investigating the special conditions of the region, and assessing the regional risks.

In agreement with the results of the present study, Patterson et al. (2020) have highlighted the importance of such issues as social participation, trust, mental readiness, operational exercises, as well as coordination, interaction, and monitoring of responsible agencies (14). Along the same lines, Liu et al. (2016) referred to teamwork, maximizing participation, building trust, coordination among people's assemblies, risk assessment, and risk management actions (5). In their research, Ashoori et al. (2018) have pointed to the importance of social participation and responsibility, implementation of communitybased programs, training local managers, and taking advantage of the capacity of neighborhoods (2).

In the same context, Falk referred to attention to disaster-prone areas, past disasters and the damages caused by them, and raising awareness on implemented measures (2013) (12). In a similar vein, Bolin and Stanford (2018) pointed to giving responsibilities to local people, creating 
local teams (rescue and relief), equipment forecasting (individual and operational) and their storage place (15). Other studies highlighted such issues as public call, motivation, division of labor, financing, synergy derived by cooperation and interaction, and having a plan in Federal Emergency Management Agency (2019) (16).

In the present study, the researcher aimed to explain the prerequisites for community-based disaster management, and it is necessary to present the results of the research in a coherent manner. Therefore, due to the restriction of available studies, other results obtained in the present research included very influential issues affecting community-based disaster management, such as legislation, policy-making, the announcement of relevant bylaws, practical actions in line with the National Preparedness and Response Plan, Emergency Response Plan (ERP), development of Emergency Operations Plan (EOP), implementation of the National Reconstruction and Rehabilitation Program, which are included in the Islamic Republic of Iran Disaster Management Law (17). Nonetheless, despite the critical importance of these issues, they have not received the attention they deserve. The aforementioned findings are some of the innovations of the present study.

Other findings of the current research were neglected in previous studies, including paying attention to mental and psychological traumas, attracting public participation, strengthening altruistic behaviors, drawing on the shared values, developing community service activities, religious, social, and cultural adaptation and interaction, considering specific climatic and geographical conditions of the region. Therefore, the mentioned issues can be regarded as other innovative results of the present study. Other results of the current research include delegation of authority to local teams, management unity, establishing a local emergency operations center (EOC), and forecasting local communication equipment.

Although these cases are implicitly cited in documents published by the Asian Disaster Preparedness Center (ADPC), they have not been explicitly emphasized in conducted studies (18). These cases can also be deemed as novel results of the present study. The undeniable importance of the role of the presence and participation of people and groups in various stages of disaster management highlights the necessity of explaining the prerequisites for community-based disaster management which were attended to in this study.

The participants in this research were selected taking into account the geographical, climatic, cultural, social, and religious diversity of different regions and from all over the country; therefore, the obtained results can be generalized to the general population in Iran. As illustrated by the results, 11 variables were recognized as prerequisites for community-based disaster management, including legal obligation, public sensitization, strategic planning, public participation, social capacity building, cohesion and empathy, action (prevention, preparedness, needs assessment, planning, response), formation and development of specialized teams, logistics and equipment forecasting, preparation, and attention to geographical conditions.

It is worth noting that the aforementioned variables encompass 54 sub-variables which can be generalized to different communities with unique features. The required measures for the successful implementation of community-based disaster risk management can be assigned to two categories: The first one encompasses the measures that require structural changes and law reform are taken at the national level and the National Disaster Management Organization of the country. The second type of measure must be implemented at the local and operational management levels.

\section{Acknowledgments}

The authors would like to express their gratitude to all those who contributed to the conduction of this research project.

\section{Conflict of Interests}

Authors declared no conflict of interests regarding the publication of the present study.

\section{References}

1. Pouraghajan M, Beikzade Y. Assessing Organizational Transformability and Its Impact on Crisis Management (Case Study: East Azerbaijan Company) Fourth National Conference on Management, Economics and Accounting, Tabriz, 2016. (In Persian)

2. Ashouri A, Khayatian M, Farzadi M. Investigating the role of community-based in crisis management, Conference on Civil Engineering, Architecture and 
Urbanism in the Islamic world, Tabriz. 2018. (In Persian)

3. Karimi K, Tagiluo A. Community-based disaster risk management towards sustainable development. Disaster Prevention and Management Knowledge (quarterly) 2020; 10(1):59-73. (In Persian)

4. Azad MA, Uddin MS, Zaman S, Ashraf MA. Community-based disaster management and its salient features: a policy approach to peoplecentered risk reduction in Bangladesh. Asia-Pacific Journal of Rural Development 2019; 29(2):60-135. https://doi.org/10.1177/1018529119898036(In Persian)

5. Liu Y, Yin K, Chen L, Wang W, Liu Y. A community-based disaster risk reduction system in Wanzhou, China. International Journal of Disaster Risk Reduction 2016; 19:379-89. https:// doi.org/10.1016/j.ijdrr.2016.09.009 (In Persian)

6. Stovall M, Smith SA, Langholz BM, Boice Jr JD, Shore RE, Anderson M, Buchholz TA, Capanu M, Bernstein L, Lynch CF, Malone KE. Dose to the contralateral breast from radiotherapy and risk of second primary breast cancer in the WECARE study. International Int J Radiat Oncol Biol Phys 2008;72(4):1021-30.

https://doi.org/10.1016/j.ijrobp.2008.02.040

7. Borrini G, Kothari A, Oviedo G. Indigenous and local communities and protected areas: Towards equity and enhanced conservation: Guidance on policy and practice for co-managed protected areas and community conserved areas. IUCN; 2004.

8. Patterson $\mathrm{O}$, Weil $\mathrm{F}$, Patel $\mathrm{K}$. The role of community in disaster response: conceptual models. Popul Res Policy Rev 2010; 29(2):127-41.

9. Bazargan A. Introduction to Qualitative and Mixed Research Methods; Common Approaches in Behavioral Sciences. Tehran. Didar. 2008. (In
Persian)

10. Hosseini KA, Izadkhah YO. From "Earthquake and safety" school drills to "safe school-resilient communities": A continuous attempt for promoting community-based disaster risk management in Iran. IJDRR 2020; 45:101512. https://doi.org/10.1016/j.ijdrr.2020.101512(In Persian)

11. Falk K. Preparing for Disaster: A Community Based Approach, 2nd Rev. Danish Red Cross, Copenhagen. 2013.

12. Pourezzat AA, Firouzpour A, Sadabadi AA. Study \& Comparison of Community-based Approach to Crisis Management in the Selected Countries. Public Pers Manage 2013; 2:37-58. (In Persian)

13. Patterson O, Weil F, Patel K. The role of community in disaster response: conceptual models. Popul Res Policy Rev 2010; 29(2):127-41.

14. Bolin R, Stanford L. The Northridge earthquake: community-based approaches to unmet recovery needs. Disasters 1998; 22(1):21-38. https:// doi.org/10.1111/1467-7717.00073

15. FEMA. IS-288.A: The Role of Voluntary Organizations in Emergency Management. Federal Emergency Management Agency: Emmitsburg. Md 2019. Available from: https://raining.fema.gov/is/ courseoverview.aspx? code=IS-288.a

16. The new law on crisis management of the Islamic Republic of Iran, by the Islamic Consultative Assembly and the Guardian Council. 2017. Available: https://www.rrk.ir/Laws/ShowLaw.aspx?Code=18237

17. Center AD. Community-based disaster risk management. United Nations economic and social commission for Asia and Pacific (UNESCAP) and European commission humanitarian aid department (ECHO). Bangkok: Asian Disaster Preparedness Center. 2008. 